\title{
Differences in Medical Error Risk among Nurses Working Two- and Three-shift Systems at Teaching Hospitals: A Six-month Prospective Study
}

\author{
Katsutoshi TANAKA ${ }^{*}$, Masaya TAKAHASHI ${ }^{2}$, Hisanori HIRO ${ }^{3}$, Mitsuru KAKINUMA ${ }^{1}$, \\ Mika TANAKA ${ }^{4}$, Naoki KAMATA ${ }^{5}$ and Hitoshi MIYAOKA ${ }^{5}$ \\ ${ }^{1}$ Department of Occupational Mental Health, Graduate School of Medical Sciences, Kitasato University, 1-15-1 \\ Kitasato, Sagamihara, Kanagawa 228-8555, Japan \\ ${ }^{2}$ National Institute of Occupational Safety and Health, 6-21-1 Nagao, Tama-ku, Kawasaki, Kanagawa 214- \\ 8585, Japan \\ ${ }^{3}$ Department of Mental Health, University of Occupational and Environmental Health, 1-1 Iseigaoka, \\ Yahatanishi-ku, Kitakyushu, Fukuoka 807-8555, Japan \\ ${ }^{4}$ School of Nursing, Faculty of Medicine, Fukuoka University, 7-45-1 Nanakuma, Jonan-ku, Fukuoka 814- \\ 0180, Japan \\ ${ }^{5}$ Department of Psychiatry, Kitasato University School of Medicine, 1-15-1 Kitasato, Sagamihara, Kanagawa \\ 228-8555, Japan
}

Received May 31, 2009 and accepted October 28, 2009

\begin{abstract}
Shift work, including night work, has been regarded as a risk factor for medical safety. However, few studies have investigated the difference in medical error risk between two- and three-shift systems. A total of 1,506 registered nurses working shifts at teaching hospitals participated in this study to evaluate the difference in medical error risk between two- and threeshift systems. After adjustment for potential confounding factors using a log Poisson generalized estimating equation model, the results showed significantly higher frequencies of perceived adverse events over 6 months in the three-shift than in the two-shift system, with estimated mean numbers of adverse events of 1.05 and 0.74 , respectively. Shorter intervals after night shifts and greater frequency of night shifts in three-shift systems, which reduce the recovery time from night shift work, may be linked to increased medical errors by nurses.
\end{abstract}

Key words: Medical error, Nurse, Three-shift system, Two-shift system, Prospective cohort study

\section{Introduction}

Improving patient safety by preventing medical errors is a socially important issue. Many studies have reported patient risks associated with medical errors and emphasized the need for implementing more patient safety measures $^{1-3)}$. In particular, shift work, including night work, has been regarded as a risk factor for safety ${ }^{4-7)}$. Shift work schedules vary depending on a variety of conditions, including timing and length of work hours; fixed or rotating scheduling; duration and direction of rotation; num-

*To whom correspondence should be addressed.

E-mail: ka-tnk@nifty.com ber of consecutive days of night work; and number of work hours per week. With respect to differences in occupational safety between 8-h shifts (three-shift system) and 12-h shifts (two-shift system), most previous studies have been conducted in industrial rather than medical fields. While some studies reported that 12 -h shift work is linked to increases in fatigue and errors, which in turn leads to a higher risk of accidents ${ }^{8-11)}$, others found no significant increase in accidents associated with a change from 8- to 12-h shift work ${ }^{12-14)}$, and no consistent conclusions have thus yet been reached. In their investigation of outcomes after changing from 8- to 12-h shift work in petrochemical plants and a fertilizer producing company, Pollock et $a l$. found an increase in the percentage of serious injuries 
and a decline in the percentage of minor injuries in petrochemical plants, but no change in the fertilizer plant. Based on these findings, they concluded that the impact of 12-h shift work varies depending on the characteristics of workers, and the working environment ${ }^{15}$.

Although several large-scale studies have investigated the impact of differences in length of shift work on health in medical fields ${ }^{16,17)}$, few of these focused on safety as an outcome. Here, we investigated the difference in medical error risk among nurses between the two- and threeshift system, with consideration to potential confounding factors, including psychological stress and work environment characteristics.

\section{Methods}

\section{Participants and procedures}

A total of 1,506 registered nurses working shifts at five teaching hospitals participated in the study. The authors also worked at these hospitals. Among the five hospitals, two (hospitals A and B) had the same type of three-shift system and three (hospitals C, D, and E) had the same type of two-shift system. Hospitals A and B employed a total of 411 and 276 shift work nurses, and C, D and E employed 573, 126, and 120, respectively. The two-shift work schedule was composed of daytime (8:00-17:00) and nighttime (16:30-8:30) shifts. The daytime work included 1-h lunch breaks. During night work, a 2-h nap and breaks between 22:00 and 4:00 were regulated. The three-shift work schedule was composed of day (8:30-17:00), evening (15:00-23:30), and night (23:00-9:00) shifts. The daytime work included 1-h lunch breaks, and the evening work included 30-min breaks. During night work, a 1.5-h nap and breaks were regulated. For both the two- and three-shift systems, the number of consecutive nights of work was, in principle, limited to two. Each hospital had irregular schedules depending on individual or other staff schedules.

The objectives and procedures of the study were explained to the nursing director and senior nursing officer in each hospital. Each senior nursing officer then orally explained the study to nurses on the ward or in the outpatient department using a study information sheet, and asked them to participate in the study. The following information was provided to the nurses: objectives and methods of the study, voluntary participation, no disadvantage from nonparticipation, option to discontinue participation in the study at any time, and confirmation of final informed consent by returning a self-report questionnaire to the investigator. The senior nursing officers were excluded from the study because they were not primarily involved in nursing cases. There were no other exclusion criteria.
The first self-report questionnaire included items concerning demographic characteristics and work conditions and was distributed to participants in November 2005. The second questionnaire, which was distributed in May 2006, included items on the frequency of self-perceived adverse events experienced in the last 6 months. All reported questionnaires were sealed in individual envelopes before collection.

The study protocol was approved by the Institutional Ethics Committees of Showa and Kitasato Universities.

\section{Measurement}

The first questionnaire included items on gender; age; number of years of nursing experience; position (chief nurse or not); alcohol consumption habit (defined as drinking at least once per week); work place; presence or absence of a ward rotation in the last 6 months; highest severity of sleepiness as assessed on the Stanford sleepiness scale during day work; frequency of sleepiness during work regardless of day or night shift; job stress; mental status; and work conditions.

Job stress was assessed using the Nursing Stress Scale (NSS) and the Effort-Reward Imbalance (ERI) questionnaire. The NSS ${ }^{18-20)}$, a well-known and widely used scale, has 7 subscales: death and dying, conflict with physicians, inadequate preparation, problems with peers and supervisors, workload, and uncertainty concerning treatment. The ERI questionnaire ${ }^{21)}$ used to assess effortreward imbalance is based on the ERI model, a theoretical concept advocated by Siegrist ${ }^{22)}$ which proposes to assess the adverse health effects of stressful experience at work ${ }^{23-25)}$. This model defines stressful experience at work as an imbalance between high effort expended and low reward received. According to the theoretical formulation, the ratio between the two scales of effort and reward (weighted by item numbers) is calculated in order to determine the degree of imbalance between high effort expended and low reward received at work. The personal characteristic of over-commitment is defined as the tendency to be absorbed in work excessively.

Mental status was assessed using the Hospital Anxiety and Depression Scale (HADS) ${ }^{26)}$, a short self-report questionnaire composed of subscales for anxiety and depression, each of which produces a score in the range of $0-21$.

To evaluate work conditions, items concerning the frequency of feeling unskilled, of time pressure, and of feeling a lack of communication among staff were investigated. These factors have been regarded as showing a relation to medical errors ${ }^{27-31)}$. The response choices were "no", "occasionally", "frequently", or "always", with "no" and "occasionally" were regarded as no, and "frequently" and "always" were regarded as yes. The same response choices and collapsing of response categories 
were applied to questions concerning the frequency of sleepiness during work. The nurse's workplace was classified into three categories: internal ward; surgical ward; and emergency room (ER) and intensive care unit (ICU), with internal wards including wards for internal medicine, dermatology, neurology, and rehabilitation; surgical wards including pediatrics, obstetrics, gynecology, ophthalmology, urology, otorhinology, anesthesiology (many patients are often hospitalized for surgery on these wards), and all surgical departments (cardiovascular surgery, gastrointestinal surgery, respiratory surgery, cerebral surgery, orthopedic surgery, and plastic surgery); and ER and ICU including pediatric and neonatal intensive care units and operating rooms.

The second questionnaire investigated the frequency of self-perceived error-related adverse events experienced in the last 6 months. In this study, an error-related adverse event was defined as an unanticipated incident in which the subject nurse made an error which resulted in harm to a patient ${ }^{32}$. To investigate the frequency of perceived adverse events in the last 6 months, the questionnaire asked "how often in last 6 months did a patient under your care experience injury or disadvantage due to an error made by you?"

\section{Statistical analyses}

A bivariate analysis was initially performed to determine the variables for multivariate analysis. Categorical variables were analyzed by Fisher's exact test, and continuous variables by the $t$-test. Several previous studies have observed large differences in the frequency of medical errors as a function of years of experience ${ }^{33-36)}$. Therefore, bivariate analysis was conducted after the entire sample was divided into tertiles of years of experience. Using a log Poisson GEE with all effects fixed, estimated mean numbers of adverse events over 6 months were obtained after adjustment for potential confounding factors. The confounding factors were the variables from the bivariate analysis that identified significant differences in at least one level of the three experience-year categories between three-shift work and two-shift work. The reason for using a log Poisson GEE was because the distribution of frequencies of adverse events was anticipated to be a Poisson distribution. Years of experience were divided into three levels and applied to the models. The statistical software SPSS version 16.0 (SPSS Inc., Chicago, IL, USA) was used for analysis. Statistical significance was set at the 0.05 level, and all tests were twotailed.

\section{Results}

Self-report questionnaires were obtained from 1,470 of the 1,506 nurses (97.6\%) doing shift work at the five hospitals. A total of 1,407 nurses $(93.4 \%)$ who provided complete responses to the questions, which included gender, age, years of experience, and frequencies of adverse events, were included in the statistical analysis. No difference was seen in gender or age between the 63 nurses who provided poor responses and the 1,407 who reported assessable information. All shift work included night work. Demographic characteristics of the study participants are shown in Table 1. Of the 1,407 participants who worked shifts, $1,330(94.5 \%)$ were female, with a mean (SD) age of 28.0 (5.9) yr and mean years of experience of 5.8 (5.4); 737 (52.4\%) worked the two-shift systems of $16 \mathrm{~h}$ night shift work while $670(47.6 \%)$ worked the three-shift system of $10 \mathrm{~h}$ night shift work.

Table 1 shows the number of adverse events during the 6-month study period, demographic characteristics of the participants, and differences in work environments. During the study period, there was a significant difference between the two- and three-shift systems in terms of mean number (SD) of perceived adverse events, at 0.9 (1.3) and $1.2(1.5)$, respectively $(p<0.05)$. The mean number (SD) of adverse events in hospitals A and B was 1.1 (1.4) and 1.3 (1.5), respectively, with no significant difference between them ( $t$-test, $p=0.13)$, while that in hospitals C, D, and E was 1.0 (1.4), 0.9 (1.1), and 1.0 (1.1), respectively, also with no significant differences between them (analysis of variance, $p=0.96$ ). A significant difference was observed for years of experience (SD) - an important confounding factor-between the two- and three-shift systems (5.3 (4.8) and 6.3 (5.6), $p<0.01)$. Division of the sample into tertiles generated groups with less than 3 yr' experience (432 nurses: $30.7 \%$ ), from 3 to $6 \mathrm{yr}$ ' experience (472: 33.5\%), and greater than $6 \mathrm{yr}$ ' experience (503: 35.8\%). The mean number (SD) of perceived adverse events with the two- and three-shift systems in these groups was 1.4 (1.6) and 1.6 (1.7) in the group with less than 3 yr' experience, 0.9 (1.2) and 1.4 (1.4) in the group with 3-6 yr' experience, and $0.6(0.9)$ and 0.8 (1.2) in the group of more than $6 \mathrm{yr}^{\prime}$ experience. The frequency of adverse events with the three-shift system was significantly higher only in the group with 3-6 yr' experience. In bivariate analysis performed with both all participants together and the participants divided into three groups according to years of experience, variables exhibiting significant differences between the two- and three-shift systems were age, number of night shifts, ERI ratios, over-commitment, gender, position, alcohol consumption habit, as well as the frequency of experiencing time pressure, lack of skills, lack of communication and sleepiness during work.

Table 2 shows the estimated mean frequencies of adverse events during the 6-month study period using a 


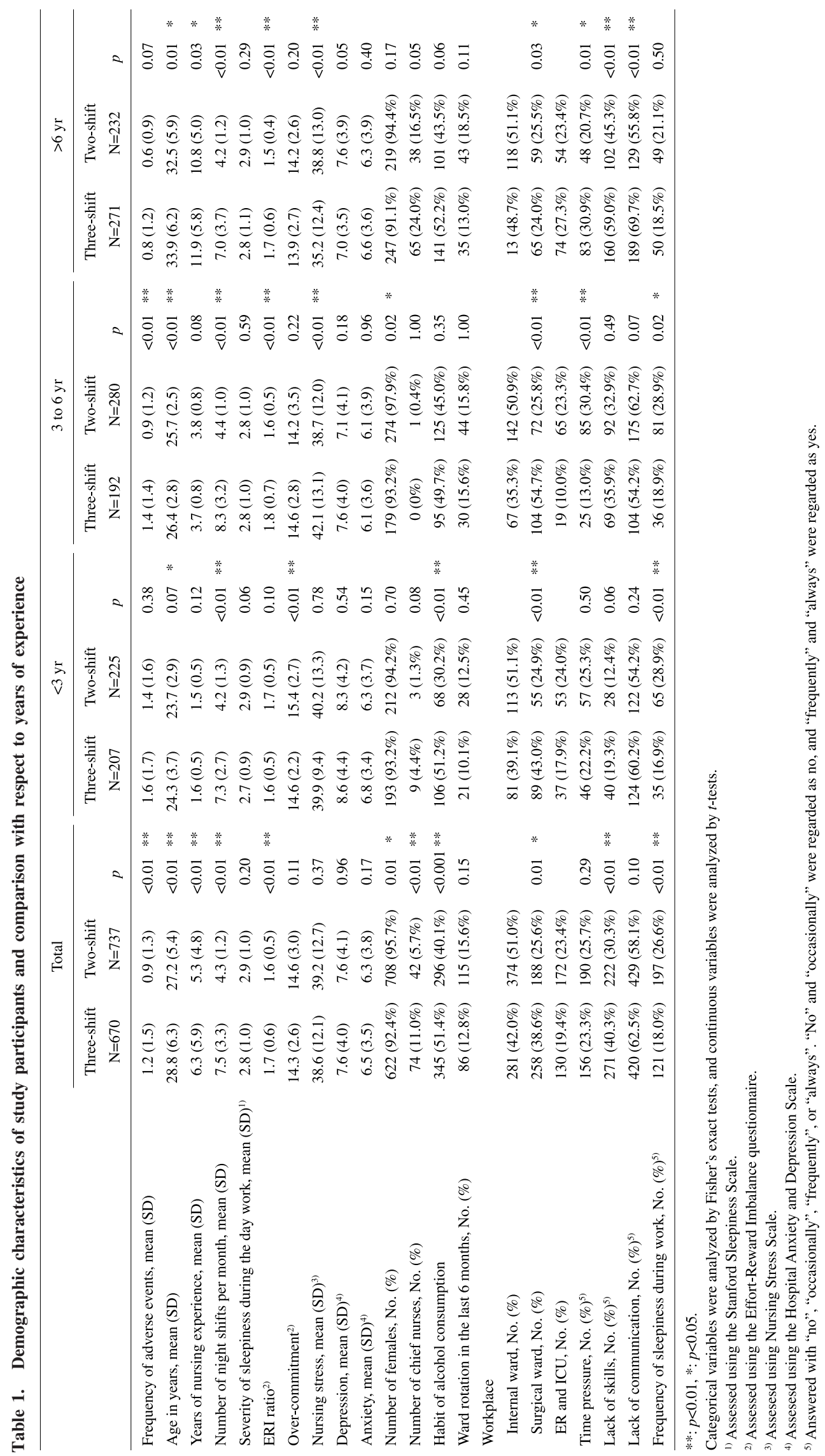


Table 2. Difference in frequencies of adverse events between three-shift system and two-shift system using log Poisson GEE analysis

\begin{tabular}{|c|c|c|c|c|c|c|c|c|c|}
\hline & \multicolumn{3}{|c|}{ Unadjusted } & \multicolumn{3}{|c|}{$\begin{array}{l}\text { Adjusted for years of experience and No. of } \\
\text { night shifts worked }{ }^{1)}\end{array}$} & \multicolumn{3}{|c|}{ Adjusted for all ${ }^{2)}$} \\
\hline & $\begin{array}{l}\text { Estimated mean } \\
\text { (SE) }\end{array}$ & $\begin{array}{l}\text { Difference } \\
(95 \% \mathrm{CI})\end{array}$ & $p$ & $\begin{array}{l}\text { Estimated mean } \\
\text { (SE) }\end{array}$ & $\begin{array}{l}\text { Difference } \\
(95 \% \mathrm{CI})\end{array}$ & $p$ & $\begin{array}{l}\text { Estimated mean } \\
\quad(\mathrm{SE})\end{array}$ & $\begin{array}{l}\text { Difference } \\
(95 \% \mathrm{CI})\end{array}$ & $p$ \\
\hline \multirow[t]{2}{*}{ Three-shift system } & $1.19(0.06)$ & & & $1.21(0.07)$ & & & $1.05(0.12)$ & & \\
\hline & & $0.24(0.09-0.38)$ & $<0.001$ & & $0.33(0.16-0.50)$ & $<0.001$ & & $0.30(0.15-0.46)$ & $<0.001$ \\
\hline Two-shift system & $0.94(0.05)$ & & & $0.89(0.05)$ & & & $0.74(0.09)$ & & \\
\hline
\end{tabular}

GEE: generalized estimation equation, SE: standard error of mean, CI: confidence interval.

1) Adjusted for years of experience and number of night shifts per month.

2) Adjusted for years of experience, number of night shifts, ERI ratios, over-commitment, gender, position, habit of alcohol consumption, workplace and frequencies of experiencing feelings (concerning work overload, time pressure, lack of skills, and sleepiness during work).

$\log$ Poisson GEE. Significant variables in the bivariate analysis except age (due to its strong correlation with years of experience) were used as independent variables. Results demonstrated higher frequencies of adverse events in the three- than in the two-shift system in the model adjusted for years of experience and number of night shifts per month, and in that adjusted for all variables. The estimated mean numbers (SE) of perceived adverse events of the two- and three-shift systems were 1.05 (0.12) and $0.74(0.09)$, respectively, and the effect size ( $95 \%$ confidence interval) was 0.30 ( 0.15 to 0.46$)$ in the model adjusted for all variables.

\section{Discussion}

Results from a log Poisson GEE with adjustment for potential confounding factors demonstrated that teaching hospital nurses doing three-shift work had a higher frequency of perceived adverse events than their counterparts doing two-shift work.

While many studies have investigated the influence of 8-h (three-shift system) and 12-h shifts (two-shift system) on safety in laboratory settings or industrial fields, no consistent conclusions have been reached. Among findings, 12-h shifts helped to increase consecutive free or leisure time, but also significantly affected accident risk ${ }^{9}$; workers in 12-h systems involving surveillance work had a higher frequency of error toward the end than at the beginning of work, in both day and night shifts, whereas counterpart workers in 8 -h shifts did not ${ }^{37)}$; and significant declines in attention were seen after $10 \mathrm{~h}$ of work, for both day and night shifts ${ }^{10)}$. In their comparison of accident rates $10 \mathrm{yr}$ before and $10 \mathrm{yr}$ after a change from 8$\mathrm{h}$ to 12 -h shifts in one company, Laundry et al. confirmed a significant decline in minor and moderate injuries, and also found a trend toward a decline, although not statistically significant, in on-the-job-accidents as a whole ${ }^{38)}$; while Lowden et al. reported that a change from 8-h to 12-h shifts was positive in most respects (satisfaction with work hours, sleep, and time for social activities) and that health, perceived accident risk, and reaction-time performance were not negatively affected ${ }^{14)}$. In contrast, two studies comparing 8-and 12-h shift systems observed no differences in workers' simple performance outcomes as assessed by reaction time measures ${ }^{13,14)}$, while a third reported no remarkable increase in accidents by manufacturing workers after a change from 8-h to 12-h shifts ${ }^{12}$. In the medical field, Macias et al. reported that the percentage of incidents, including needle-stick and bio-fluid exposure accidents, increased in the $2 \mathrm{~h}$ before the end of a 12-h shift, but not in the $2 \mathrm{~h}$ before the end of an 8 -h shift ${ }^{39}$. Because two-shift systems in other countries usually involve 12 -h shifts, in contrast to the 16 h' night work in Japanese two-shift systems, these results from other countries cannot be directly applied to Japanese cases of two-shift work. In any case, these discrepancies among previous findings for worker error clearly point to the need for additional in-depth studies. Pollock et al. ${ }^{15)}$ and Lowden et al. ${ }^{14)}$ suggest that they can be attributed to differences in work time and sequential work patterns, worker characteristics, and work environment. Studies investigating the impact of differences between two- and three-shift systems need to clearly describe how they adjusted for confounding factors. A strength of the present study is its adjustment for more confounding factors than previous studies.

In the present study, bivariate analysis demonstrated that only the nurses with 3-6 yr' experience working the three-shift system reported a significantly higher frequency of adverse events. This finding may be related to the fact that this group also had the highest NSS scores and ERI ratios. It has been reported that elevated stressors increase the risk of medical error ${ }^{33)}$. Dorrian et al. reported that one of the most important predictors of nurse error was stress ${ }^{40)}$. Nurses with 3-6 yr' experience are expected to serve not only as full-fledged nurses who satisfactorily manage their nursing duties, but also to play a central role in educating and supporting novice nurses. Due to the greater frequency of shift work, these pressures and burdens may accrue more frequently to nurses 
working three-shift systems than their counterparts working in two-shift systems.

Following adjustment for years of experience, NSS score, ERI ratio, and several other potential confounders, the present results demonstrated that nurses in three-shift work had a higher frequency of perceived adverse events than their counterparts working two-shift schedules. This difference may be attributable by several possible factors. Previous research has indicated a higher risk of incidents during night shifts, 7,41). In our study, however, total hours of night shift work per month did not substantially differ among systems, with nurses working the twoshift system having an average of 4.3 night shifts and $60.02 \mathrm{~h}$ of night work ( 4.3 shifts $4.3 \times 14 \mathrm{~h}$ ) per month versus 7.5 night shifts and a total of $63.75 \mathrm{~h}$ of night work $(7.5$ shifts $\times 8.5 \mathrm{~h})$ in those working the three-shift system. Taking a nap during night shifts is reported to be effective in reducing the risk of medical errors ${ }^{42,43)}$. While both the two- and three-shift systems in the present study were regulated to offer a nap opportunity during night shifts, the mandated $2 \mathrm{~h}$ for the former may have provided a more favorable effect than the $1 \mathrm{~h}$ for their three-shift counterparts. Unfortunately, we did not investigate napping behavior here, and this assumption needs to be tested.

Citing the finding that hospital nurses in two-shift work involving 16-h night shifts were less busy and had longer off-shift time after night shifts than those in three-shift work with 8-h night shifts, Takahashi et al. suggested that these factors help reduce the work-related health problems induced by long night shifts ${ }^{44)}$. Longer intervals after night work may enable longer main sleep, and guarantee sufficient recovery time from night shift work to spend on stress coping, which may in turn be linked to reductions in errors during work hours ${ }^{14,45}$. In the present study, the mean number of night shifts per month significantly differed $(p<0.01)$ between the two- and three-shift systems (Table 1). Moreover, because nurses in the threeshift systems work not only more night shifts, but also work evening shifts, they are more likely to be exposed to artificial lighting at night, and therefore have less time for exposure to daylight. This pattern of light and darkness may disturb circadian rhythm ${ }^{46)}$, and the resulting increase in fatigue and decrease in attention would likely increase the risk of medical error. The need for more studies focusing on health hazards faced by health care workers, including nurses, as well as to the assessment of preventive measures has been widely acknowledged ${ }^{47)}$. Studies of care workers in nursing homes, currently the subject of much attention in Japan, increasingly demonstrate associations between shift work and worker sleep and musculoskeletal disorders ${ }^{48,49)}$, and additional studies with a wide range of health care workers are neces- sary. Given that the interaction between shift work and psychosocial factors is an important research theme in fields other than health care ${ }^{50)}$, a wide range of studies of shift work and worker health in a range if fields is anticipated.

\section{Limitations}

In addition to those mentioned above, several other limitations in generalizing our results warrant mention. First, adverse events were not assessed by interview or through objective observation, but were self-reported on an anonymous basis. Although some measurement bias may have occurred, anonymous reporting is associated with a significant increase in the rate of reported medical errors $^{51-53)}$. Further, as participants were required to recall adverse events during the previous 6-month period, some recall bias may also have been present. Subjects were not asked about the time or details of incidents, which prevented the examination of event time and severity. Second, we did not identify working hours, which are thought to have a strong relationship with incident occurrence. However, as all study hospitals had an administrative policy to reduce overtime (defined as working more than $40 \mathrm{~h}$ per week) to less than $20 \mathrm{~h}$ per month, we speculate that there were no significant differences between the hospitals, and that total working hours per month were in the range of approximately 160 to 180 . Background safety and medical error prevention policies among hospitals were not completely concordant, but an accurate evaluation of these would be extremely difficult. Nevertheless, given that all five hospitals are teaching institutions and share safety provisions such as providing incident management systems and on-the-job education programs for incident prevention, significant differences among them are unlikely.

\section{Acknowledgement}

The present study was supported by a Grant-in-Aid (No. 16591159) from the Japan Society for the Promotion of Science.

\section{References}

1) Leape LL (1994) Error in medicine. JAMA 272, 1851-7.

2) Classen DC, Pestotnik SL, Evans RS, Lloyd JF, Burke JP (1997) Adverse drug events in hospitalized patients. Excess length of stay, extra costs, and attributable mortality. JAMA 277, 301-6.

3) Committee on Quality of Health Care in America, Institute of Medicine (2000) To Err Is Human: Building a Safer Health System, Kohn L, Corrigan J and Donaldson M (Eds.), National Academy Press, Wasington, DC. 
4) Smith L, Folkard S, Poole CJ (1994) Increased injuries on night shift. Lancet 344, 1137-9.

5) Costa G (2003) Shift work and occupational medicine: an overview. Occup Med (Lond) 53, 83-8.

6) Folkard S, Tucker P (2003) Shift work, safety and productivity. Occup Med (Lond) 53, 95-101.

7) Folkard S, Lombardi DA, Tucker PT (2005) Shiftwork: safety, sleepiness and sleep. Ind Health 43, 20-3.

8) Rosa RR (1995) Extended workshifts and excessive fatigue. J Sleep Res 4, 51-6.

9) Rosa RR, Bonnet MH, Cole LL (1998) Work schedule and task factors in upper-extremity fatigue. Hum Factors 40, 150-8.

10) Fischer FM, de Moreno CR, Notarnicola da Silva Borges F, Louzada FM (2000) Implementation of 12hour shifts in a Brazilian petrochemical plant: impact on sleep and alertness. Chronobiol Int 17, 521-37.

11) Macdonald W, Bendak S (2000) Effects of workload level and 8- versus 12-h workday duration on test battery performance. Int J Ind Ergon 23, 399-416.

12) Johnson MD, Sharit J (2001) Impact of achenge from an 8-h to a 12-h shift schedule on workers and occupational injury rates. Int J Ind Ergon 27, 303-19.

13) Axelsson J, Kecklund G, Åkerstedt T, Lowden A (1998) Effects of alternating 8- and 12-hour shifts on sleep, sleepiness, physical effort and performance. Scand J Work Environ Health 24 (Suppl 3), 62-8.

14) Lowden A, Kecklund G, Axelsson J, Åkerstedt T (1998) Change from an 8-hour shift to a 12-hour shift, attitudes, sleep, sleepiness and performance. Scand J Work Environ Health 24 (Suppl 3), 69-75.

15) Pollock C, Cross R, Taylar P (1994) Influences of 12 hour versus 8 hour shiftwork on injury patterns. International Ergonomics Association. Ergonomie et Lieux de Travail 33, 903-6.

16) Lipscomb JA, Trinkoff AM, Geiger-Brown J, Brady B (2002) Work-schedule characteristics and reported musculoskeletal disorders of registered nurses. Scand J Work Environ Health 28, 394-401.

17) Trinkoff AM, Storr CL (1998) Work schedule characteristics and substance use in nurses. Am J Ind Med 34, 266-71.

18) Gray-Toft P, Anderson JG (1981) The nursing stress scale: development of an instrument. J Behav Assess 3, 11-23.

19) Funashima N, Kameoka T, Sugimori M (1997) Reliability and Validity of Japanese version of Role conflict and Ambiguity Scale (RCAS) and that of Nursing Stress Scale (NSS): development of Instruments to test the King's Theory of Goal Attainment Chiba Kankaishi 3, 17-23 (in Japanese).

20) French SE, Lenton R, Walters V, Eyles J (2000) An empirical evaluation of an expanded Nursing Stress Scale. J Nurs Meas 8, 161-78.

21) Tsutsumi A, Nagami M, Morimoto K, Matoba T (2002) Responsiveness of measures in the effort-reward imbalance questionnaire to organizational changes: a valida- tion study. J Psychosom Res 52, 249-56.

22) Siegrist J (1996) Adverse health effects of higheffort/low-reward conditions. J Occup Health Psychol 1, 27-41.

23) Bosma H, Peter R, Siegrist J, Marmot M (1998) Two alternative job stress models and the risk of coronary heart disease. Am J Public Health 88, 68-74.

24) Fahlén G, Knutsson A, Peter R, Åkerstedt T, Nordin M, Alfredsson L, Westerholm P (2006) Effort-reward imbalance, sleep disturbances and fatigue. Int Arch Occup Environ Health 79, 371-8.

25) Kouvonen A, Kivimäki M, Virtanen M, Heponiemi T, Elovainio M, Pentti J, Linna A, Vahtera J (2006) Effortreward imbalance at work and the co-occurrence of lifestyle risk factors: cross-sectional survey in a sample of 36,127 public sector employees. BMC Public Health 6, 24 .

26) Zigmond AS, Snaith RP (1983) The hospital anxiety and depression scale. Acta Psychiatr Scand 67, 361-70.

27) Ootim B (2002) Error making. Part 2: Identifying the causes in nursing. Nurs Manag (Harrow) 9, 25-9.

28) Ann Page (2003) Keeping patients safe: Institute of Medicine looks at transforming nurses' work environment, National Academy Press, Washington, DC.

29) Sutcliffe KM, Lewton E, Rosenthal MM (2004) Communication failures: an insidious contributor to medical mishaps. Acad Med 79, 186-94.

30) Haw CM, Dickens G, Stubbs J (2005) A review of medication administration errors reported in a large psychiatric hospital in the United kingdom. Psychiatr Serv 56, 1610-3.

31) Seki Y (2008) Working condition factors associated with time pressure of nurses in Japanese hospitals. J Occup Health 50, 181-90.

32) Leape LL, Lawthers AG, Brennan TA, Johnson WG (1993) Preventing medical injury. QRB Qual Rev Bull 19, 144-9.

33) Schulmeister L (1999) Chemotherapy medication errors: descriptions, severity, and contributing factors. Oncol Nurs Forum 26, 1033-42.

34) Phillips J, Beam S, Brinker A, Holquist C, Honig P, Lee LY, Pamer C (2001) Retrospective analysis of mortalities associated with medication errors. Am J Health Syst Pharm 58, 1835-41.

35) Seki Y, Yamazaki Y (2006) Effects of working conditions on intravenous medication errors in a Japanese hospital. J Nurs Manag 14, 128-39.

36) Tang FI, Sheu SJ, Yu S, Wei IL, Chen CH (2007) Nurses relate the contributing factors involved in medication errors. J Clin Nurs 16, 447-57.

37) Mitchell RJ, Williamson AM (2000) Evaluation of an 8 hour versus a 12 hour shift roster on employees at a power station. Appl Ergon 31, 83-93.

38) Laundry BR, Lees RE (1991) Industrial accident experience of one company on 8- and 12-hour shift systems. J Occup Med 33, 903-6.

39) Macias DJ, Hafner J, 2nd, Brillman JC, Tandberg D 
(1996) Effect of time of day and duration into shift on hazardous exposures to biological fluids. Acad Emerg Med 3, 605-10.

40) Dorrian J, Tolley C, Lamond N, Van Den Heuvel C, Pincombe J, Rogers AE, Drew D (2008) Sleep and errors in a group of Australian hospital nurses at work and during the commute. Appl Ergon 39, 605-13.

41) Gold DR, Rogacz S, Bock N, Tosteson TD, Baum TM, Speizer FE, Czeisler CA (1992) Rotating shift work, sleep, and accidents related to sleepiness in hospital nurses. Am J Public Health 82, 1011-4.

42) Arora V, Dunphy C, Chang VY, Ahmad F, Humphrey HJ, Meltzer D (2006) The effects of on-duty napping on intern sleep time and fatigue. Ann Intern Med 144, 792-8.

43) Smith-Coggins R, Howard SK, Mac DT, Wang C, Kwan S, Rosekind MR, Sowb Y, Balise R, Levis J, Gaba DM (2006) Improving alertness and performance in emergency department physicians and nurses: the use of planned naps. Ann Emerg Med 48, 596-604.

44) Takahashi M, Fukuda H, Miki K, Haratani T, Kurabayashi L, Hisanaga N, Arito H, Takahashi H, Egoshi M, Sakurai M (1999) Shift work-related problems in 16-h night shift nurses (2): Effects on subjective symptoms, physical activity, heart rate, and sleep. Ind Health 37, 228-36.

45) Totterdell P, Spelten E, Smith L, Barton J, Folkard S (1995) Recovery from work shifts: how long does it take? J Appl Psychol 80, 43-57.
46) Borugian MJ, Gallagher RP, Friesen MC, Switzer TF, Aronson KJ (2005) Twenty-four-hour light exposure and melatonin levels among shift workers. J Occup Environ Med 47, 1268-75.

47) Smith DR, Leggat PA, Araki S (2007) Emerging occupational hazards among health care workers in the new millennium. Ind Health 45, 595-7.

48) Takahashi M, Iwakiri K, Sotoyama M, Higuchi S, Kiguchi M, Hirata M, Hisanaga N, Kitahara T, Taoda K, Nishiyama K (2008) Work schedule differences in sleep problems of nursing home caregivers. Appl Ergon 39, 597-604.

49) Takahashi M, Iwakiri K, Sotoyama M, Hirata M, Hisanaga N (2009) Musculoskeletal pain and night-shift naps in nursing home care workers. Occup Med (Lond) 59, 197-200.

50) Takahashi M, Nakata A, Haratani T, Otsuka Y, Kaida K, Fukasawa K (2006) Psychosocial work characteristics predicting daytime sleepiness in day and shift workers. Chronobiol Int 23, 1409-22.

51) Liang BA (1999) Error in medicine: legal impediments to U.S. reform. J Health Polit Policy Law 24, 27-58.

52) Cohen MR (2000) Why error reporting systems should be voluntary. BMJ 320, 728-9.

53) Taylor JA, Brownstein D, Klein EJ, Strandjord TP (2007) Evaluation of an anonymous system to report medical errors in pediatric inpatients. J Hosp Med 2, 226-33. 